\title{
Über die Autoren/Abstracts
}

\section{Ernst Apeltauer}

Prof. Dr.; Deutsch als Zweit und Fremdsprache; Universität Flensburg; Forschungsschwerpunkte: Erst- und Zweitsprachenerwerb, interkulturelle Kommunikation. Arbeitsschwerpunkte: Sprachförderung, Fachsprachen und Verständlichkeit.

\section{Sandra Döring}

DAAD-Lektorin, University of Kent (Großbritannien). Besondere Forschungsinteressen: Prosodie und Syntax sowie deren Vermittlung im DaF-Unterricht. Promotionsprojekt: Parenthesen in der deutschen Gegenwartssprache im binationalen Promotionsverfahren (Universität Leipzig und Vrije Universiteit Amsterdam).

\section{Hannele Kara}

geb. 1954; Deutschlehrerin und Lehrerausbildnerin an der Normalschule der Universität Jyväskylä Finnland; postgraduales Studium: Dissertation zum Thema »Portfolio als Evaluationsform von mündlichen Leistungen " an der erziehungswissenschaftlichen Fakultät der Universität Jyväskylä Finnland (Betreuung durch Prof. Pauli Kaikkonen, Universität Jyväskylä Finnland)

\section{Marina Vollstedt}

Dr. phil. (Germanistik); Studium der Germanistik, Geschichte und Russistik in Kiel und St. Petersburg. Von 2000 bis 2004 DAAD-Lektorin an der Moskauer Staatlichen Lomonosov-Universität (2000-2004), Referentin für Personalentwicklung in der Axel Springer AG (seit 2005). Gründerin und Koordinatorin des Programms »Germanisten in die Wirtschaft« bis 2004. Forschungs- und Arbeitsgebiete: Unternehmenskommunikation, Soziolinguistik, Landeskundedidaktik; Hochschulmarketing und Personalrekrutierung.

\section{Stephan Walter}

Dr. phil. (Übersetzungswissenschaft); Diplom-Dolmetscherstudium (Russisch, Spanisch) in Heidelberg, Granada und St. Petersburg. DAAD-Lektor am Moskauer Energetischen Institut (1996-1999) sowie an der Staatlichen Linguistischen Universität Moskau (seit 2001). Seit 2004 Koordinator des Moskauer Programms »Germanisten in die Wirtschaft«. Forschungsund Arbeitsgebiete: Übersetzungsdidaktik, Fachsprachen; Curriculum-Entwicklung für Übersetzerstudiengänge und berufsorientierende Zusatzprogramme, Hochschullehrerfortbildung im Bereich Übersetzungsdidaktik. 


\begin{tabular}{|c|c|c|c|}
\hline 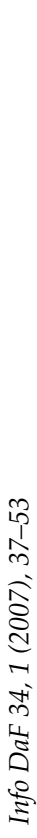 & 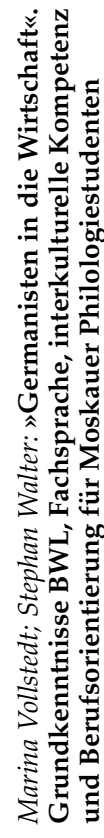 & 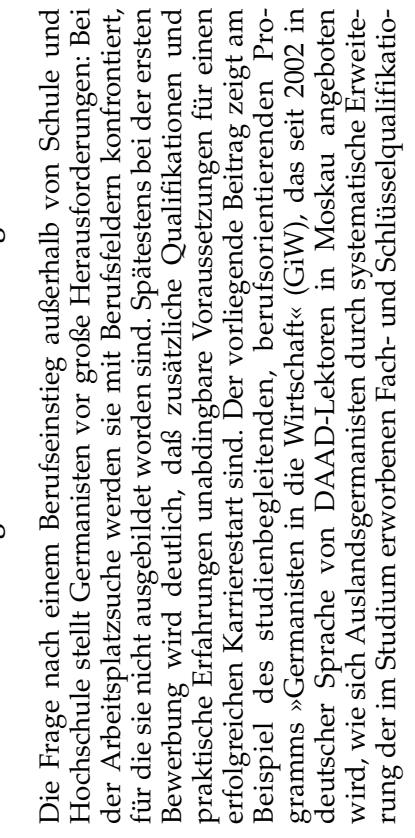 & 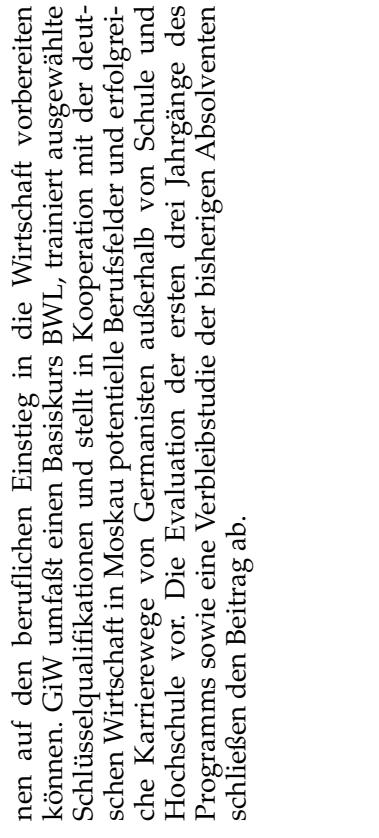 \\
\hline 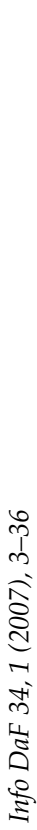 & 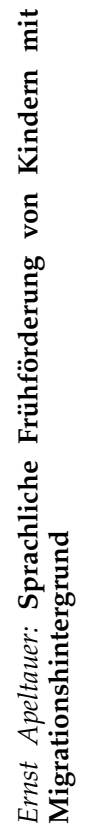 & 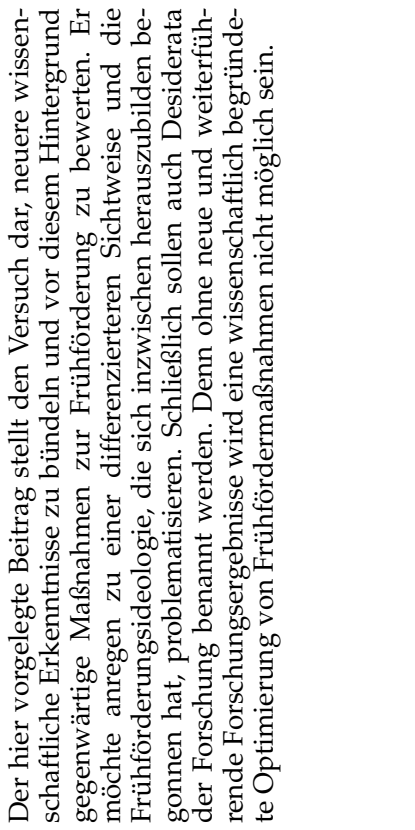 & 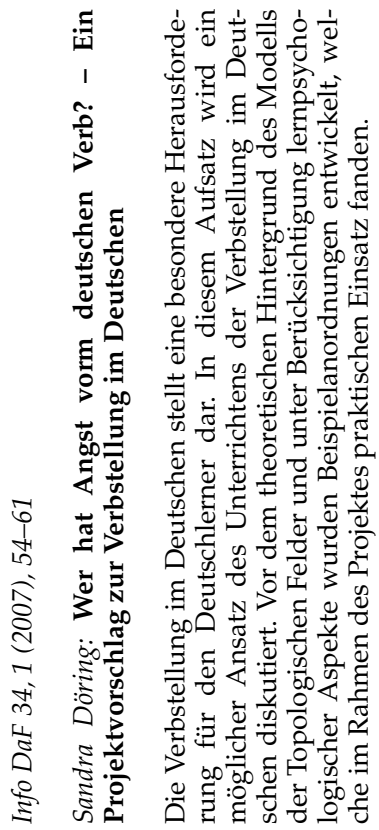 \\
\hline
\end{tabular}




\begin{tabular}{|c|c|c|c|}
\hline 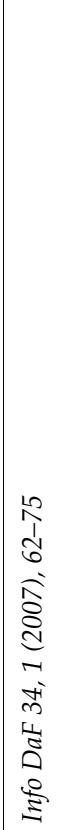 & 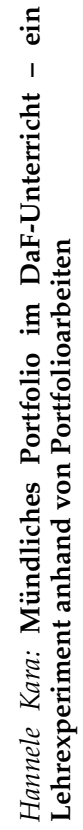 & 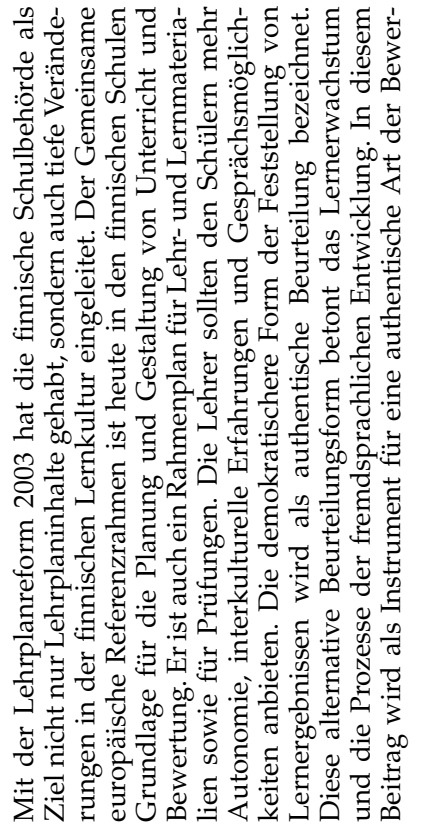 & 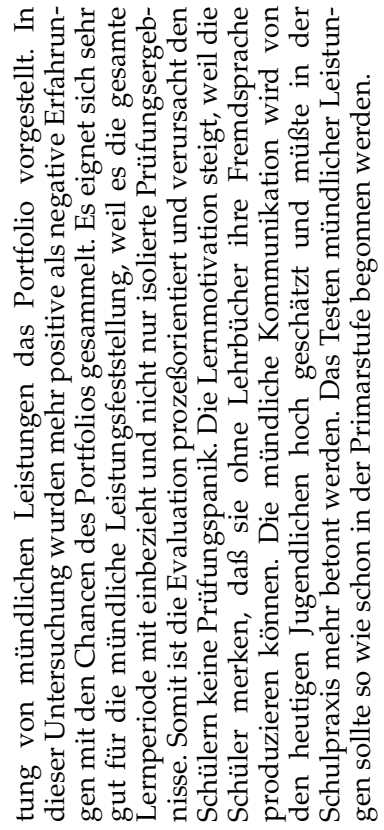 \\
\hline
\end{tabular}

